\title{
UPP e UPP Social - novas modulações para cuidar da vida no e do planeta
}

UPP e UPP Social - new modulations to take care of life on and of the planet UPP e UPP Social - nuevas modulaciones para cuidado de la vida en y del planeta

\begin{abstract}
Mayara de Martini Cabeleira
Estudante de Ciências Sociais na Pontifícia Universidade Católica de São Paulo e pesquisadora no NU-SOL - Núcleo de Sociabilidade Libertária do Programa de Estudos Pós-Graduados em Ciências Sociais PUC-SP. Em agosto de 2012 concluiu a pesquisa de iniciação científica (PIBIC - CNPq) 'UPP e UPP Social - novas modulações de segurança, dispositivos para cuidar da vida no e do planeta' sob orientação do Prof. Dr. Edson Passetti. Em novembro de 2013, concluiu a pesquisa de iniciação científica sob mesma orientação, com o projeto 'Políticas de segurança e de pacificação: os programas UPP e UPP Social' financiado pela FAPESP.

E-mail: mayarademartini@yahoo.com
\end{abstract}

\section{Resumo}

A caracterização das favelas cariocas como lugares perigosos e inseguros fomentou o desenvolvimento da atual política de pacificação em vigor desde o final de 2008. O programa composto por UPP e UPP Social, visa 're'tomar territórios ocupados por traficantes para acabar com o controle exercido por grupos organizados ostensivamente armados. Afirmando a necessidade de se promover cidadania, desenvolvimento social, econômico e sustentável, a política de pacificação convoca a população a participar da estratégia de segurança, fazendo funcionar a lógica policial a partir da aliança cidadão-estado. Este artigo pretende mostrar como a noção de segurança humana e cidadã vem funcionando na cidade do Rio de Janeiro a partir de uma pesquisa que analisou dados empíricos disponibilizados em diversas mídias, além de diretrizes internacionais. Busca-se aqui, explicitar a modulação de uma política de segurança com interesses econômicos.

Palavras-chave: Política de pacificação; Segurança humana; Segurança cidadã.

\begin{abstract}
The characteristic of the "favelas" (slums) from Rio de Janeiro as dangerous and unsafe places fomented the development of the current politician of pacification since the end of 2008 . The program composed by UPP and UPP social, has in view re-take occupied territories by dealers in order to finish with the control made by organized groups set up with a big quantity of guns.
\end{abstract}


Stating the needs to promote citizenship, social, economic and sustainable developing, the pacification policy call population to participate of the insurance strategy, making the cop logic work from the partnership citizen-state. This article intends to show how the human and citizen insurance have been working in the city of Rio de Janeiro, taking a research which analysed empirical data available in serveral mídias, besides the internacional guidelines. Our goal here is to show the modulation of an insurance policy with economic interests.

Keywords: Politician of pacification; Human security; Citizen security.

\section{Resumen}

La caracterización de las 'favelas' como lugares peligrosos e inseguros fomentaron el desarrollo de la política de pacificación en curso desde el final de 2008. El programa que comprende UPP y UPP Social, consta recuperar los territorios ocupados por traficantes de drogas para detener el control ejercido por los grupos organizados ostensiblemente armados. Afirmando la necesidad de promover la ciudadanía, el desarrollo social, económico y sostenible, la política de pacificación invita al público a participar del estrategia de seguridad, accionando la lógica de la policía con una alianza ciudadano-estado. Este artículo tiene como objetivo mostrar cómo la noción de seguridad humana y ciudadana ha estado trabajando en la ciudad de Rio de Janeiro a partir de una investigación que analizó los datos empíricos disponibles en varios medios de comunicación y directrices internacionales. Trato de hacer explícita la modulación de una política de seguridad con intereses económicos.

Palabras clave: Política de pacificación; Segurança humana; Seguridad ciudadana.

\section{UPP e UPP Social - novas modulações para cuidar da vida no e do planeta}

A cidade do Rio de Janeiro, cartão-postal do Brasil por sua beleza singular, vive nos dias de hoje sob efeitos relevantes do desenvolvimento econômico, social e ambiental sustentável no país. Após alguns anos de crise política, voltou nos últimos anos a recuperar sua proeminência e desenvolver importância econômica ao conquistar competições para sediar megaeventos, consolidando parcerias com grandes empresas para elaboração de variadas reformas e construções empreendedoras de reestruturação da cidade. $\mathrm{O}$ atual momento vem sendo chamado por idealizadores das chamadas "transformações da cidade" como a década de ouro (2011 -2020) do Rio de Janeiro. 
Em meio dessa ebulição da cidade, muitos programas e projetos destinados ao mar, asfalto e morros entraram em vigor. São de grande visibilidade projetos como Porto Maravilha e Transcarioca, junto aos programas Morar Carioca, Programa de Aceleração do Crescimento (PAC 2), Unidade de Polícia Pacificadora (UPP), UPP Social e Operação Choque de Ordem. Dois deles dedicados a enfrentar uma pauta antiga e que voltou a aparecer como problema central da cidade neste cenário: a segurança.

Neste artigo procuro situar as relações constatadas a partir de pesquisa empírica em favelas do Rio de Janeiro e documentação sobre o funcionamento da atual política de pacificação que se pauta em princípios como o de segurança cidadã e segurança humana com a finalidade de possibilitar novas condutas. Apresento, inicialmente, as procedências das noções de segurança atreladas às recomendações da cultura de paz a partir da leitura e análise de documentos que tem por metas estabelecer diretrizes planetárias de institucionalização. Em seguida, situo a perspectiva analítica de referência foucaultiana da qual lanço mão para sinalizar a tecnologia de poder que conduz condutas esperadas e descrevo as Unidades de Polícia Pacificadora acompanhada do uso que faz das tecnologias de monitoramento com base nas mídias digitais do próprio programa de pacificação Rev. Polis e Psique, 2013; 3(3):72-86 e também em notícias de jornais. Por fim, situo as ações da UPP Social e os seus desdobramentos em torno da emergência de um mercado que, pelo viés do discurso da segurança, legitima a polícia para tudo e em todos.

Com a atual segmentação da segurança, pode-se dizer que a fração atuante a partir de 2008 na cidade do Rio de Janeiro por meio da UPP é a da segurança humana cuja finalidade está em reduzir os índices de violência e prevenir os conflitos territoriais entre diferentes grupos organizados do tráfico e desses grupos com a polícia, mas também por buscar combater a pobreza, a desigualdade e a injustiça social levando sempre em conta os direitos humanos (Cf. Segurança Humana e a Paz no Brasil).

Suas procedências estão nos acordos internacionais que ganharam intensidade na década de 1990 com preocupações voltadas aos cuidados com o meio ambiente entre países desenvolvidos e emergentes. Embaladas nas discussões ambientais, as preocupações para além da vida do planeta podem ser observadas tanto quanto as preocupações com a segurança da vida no planeta. Em movimentos de corrente $e c o^{l}$, é possível notar a presença de discussões referentes à recuperação e manutenção da qualidade de vida em um planeta que deve atingir o desenvolvimento econômico, social e ambiental sustentável e, em nome da segurança 
humana, cultivar uma cultura de paz, caracterizada agora por valores e condutas tolerantes e não violentas.

Em busca de um planeta seguro e população assegurada, uma variedade de cartilhas e de recomendações surge no cenário das políticas globais. Essas recomendações aos governos se desdobram em mais cartilhas e mais recomendações, que passam a ser elaboradas localmente. Em relação às recomendações globais, sucederam-se muitos encontros entre autoridades a fim de se pensar ações que promovessem a preservação do meio ambiente e o desenvolvimento de ações sustentáveis. Mais tarde, articularam-se estratégias de erradicação da pobreza, diminuição da violência, participação política, promoção da cidadania e desenvolvimento da cultura de paz, sendo esta última um programa disseminado pela UNESCO desde 2000, visando construir cidades justas, democráticas, sustentáveis e, o mais importante, seguras (Cf. Manifesto 2000 UNESCO - Por uma Cultura de Paz e Não-violência).

Nesse contexto, a segurança ocupa um lugar de destaque e passa a ser pensada por meio de uma ordem democrática e humanizada que atua com polícias integradas na prevenção e controle aos episódios de violência. Atendendo a esta expectativa, a Organização das Nações Unidas (ONU) criou o Programa Conjunto Segurança com Rev. Polis e Psique, 2013; 3(3):72-86
Cidadania cujo objetivo é expandir o processo de articulação de todas as forças da sociedade e formas de governo no combate à criminalidade. O Programa funciona de modo que cada representante dessas forças (de governos, instituições, fundações, coletivos, ONGs, etc.) se prontifique a ser corresponsável nos planejamentos e controles de operações, assim como do desenvolvimento de técnicas de prevenção, mediação, negociação e investigação de conflitos sociais e crimes. Interessa aí, um cidadão que seja o centro do conceito de segurança para constituição da segurança humana.

Documentos oficiais, cartilhas elaboradas por projetos sociais, programas e projetos das prefeituras, governos estaduais e federais não cessam em reproduzir as recomendações como regulações em torno de um futuro compatível ao apresentado acima. Pouco se fala da segurança implicada em uma racionalidade de aperfeiçoamento dos mecanismos jurídico-legais que se liga ao que Michel Foucault chamou de tecnologia do poder.

$\mathrm{Na}$ perspectiva de Michel Foucault, a segurança do Estado moderno funciona de acordo com a Razão de Estado, na busca pela prevenção de guerras entre Estados e combate a ameaça à paz interna. A racionalidade política é caracterizada pela "integração dos indivíduos em uma comunidade ou em uma totalidade como resultado de uma 
relação permanente entre uma individualização cada vez maior e a consolidação desta totalidade" (Foucault, 1991, p.241), desenvolvida no curso das sociedades ocidentais - primeiramente como poder pastoral e mais tarde na Razão de Estado, que será encarada pelo filósofo, como aquilo que forma a noção de política da população.

Como para Foucault, o poder será sempre pertencente à ordem do governo, ou seja, à da condução de condutas, a Razão de Estado por ele equacionada se desenhou entre dois grandes saberes ou tecnologias políticas: a tecnologia diplomático-militar (que procura alianças e fortalecimento do exército) e a polícia (buscando fortalecer o Estado desde seu interior). Levando em conta essa perspectiva e sua noção de polícia, Foucault é contundente ao afirmar que o objeto da polícia é a vida - a polícia engloba tudo, desde as relações entre os homens e suas relações com as coisas até suas relações de propriedade, produção e comércio. Será então a Razão de Estado, junto com a polícia, relevantes à construção do que Foucault chamou de biopolítica. A noção de biopolítica é uma tecnologia de poder que vai se enraizando gradualmente a partir de um biopoder, que não descarta as disciplinas e preocupa-se "com as relações entre espécie humana, os seres humanos enquanto espécie, enquanto seres vivos, e seu meio, seu meio de existência" (Foucault, 2010: 206).
Anteriormente a análise do biopoder realizada por Michel Foucault, o autor trabalhou com a noção de Sociedade Disciplinar onde o poder se exercia ainda de outra maneira,

esse poder sobre a vida desenvolveu-se a partir do século XVII, em duas formas principais; que não são antitéticas e constituem, ao contrário, dois polos de desenvolvimento interligados por todo um feixe intermediário de relações. Um dos polos, o primeiro a ser formado, ao que parece, centrou-se no corpo como máquina: no seu adestramento, na ampliação de suas aptidões, na extorsão de suas forças, no crescimento, paralelo de sua utilidade e docilidade, na sua integração em sistemas de controle eficazes e econômicos - tudo isso assegurado por procedimento de poder que caracterizam as disciplinas: anátomopolitíca do corpo humano (Foucault, 1988: 151).

Ainda em sua perspectiva, é necessário situar sua noção que estuda as maneiras de governar, a governamentalidade. No que se refere a sua definição, pode-se dizer que esta governamentalidade não deixa de lado a relação do sujeito consigo mesmo, mas tem como alvo principal a população e por forma a economia política, sendo os dispositivos de segurança seu instrumento técnico. A governamentalidade é aquilo que conduz as condutas e o esperado bom 
governo do Estado, o que então passa a ser denominado como polícia.

Se as primeiras competências do Estado eram a guerra e a paz (em busca de justiça) e pouco depois a manutenção da ordem e organização da riqueza, no século XVIII acrescenta-se uma nova função: fornecer bem-estar, saúde e longevidade à população. A partir dessa nova envergadura, a doença dos pobres insere-se no problema geral das populações, inaugurando o que Foucault chamou de polícia médica. A medicalização dos espaços pretende uma nova configuração do território, fazendo surgir, então, as chamadas políticas higienistas que chegaram ao Brasil ainda no período imperial, tendo muitos desdobramentos nos cortiços e favelas da cidade do Rio de Janeiro, do século XIX ao XXI.

\section{Pacificação e tecnologias de monitoramento}

Em janeiro de 2008, a Primeira Conferencia Nacional de Segurança Públi$c a$, organizada pela Secretaria Nacional de Segurança Pública inserida no Ministério da Justiça, resultou no documento Democracia e Participação no contexto da crise da representação que anunciava, a partir de uma proposta democrática, a importância do cidadão em criar alianças com as polícias e o governo, para que a sociedade civil partici- pe ativamente na fiscalização das políticas públicas. Propõem-se além de uma segurança cidadã — onde não só a segurança do Estado está em jogo como também a segurança da vida da população —, uma segurança ajustada às exigências dos indivíduos participativos.

Esse documento aqueceu as discussões em torno de uma reformulação das políticas de segurança pública no Brasil e desde então, é possível constatar uma mobilização das prefeituras para criar novas estratégias locais e regionais de segurança que estejam articuladas com as propostas internacionais de cultura de paz (Cf. Cultura de paz (UNESCO), 2000; DHNET Direitos Humanos, 2000; Cultura de paz: da reflexão à ação, 2010).

Atendendo a estas expectativas, aos acordos e cartilhas globais e aos pré-requisitos das organizações dos megaeventos (Rio+20, Jornada Mundial da Juventude, Copa do Mundo 2014 e Olimpíadas 2016), somadas à questão do narcotráfico, a cidade do Rio de Janeiro foi a primeira grande metrópole do Brasil a criar uma gestão de segurança pública a partir do princípio de polícia de proximidade, uma das maneiras de articular segurança cidadã. A constante expansão territorial das favelas, o fortalecimento do narcotráfico, o aumento dos índices da chamada "violência urbana" e os conflitos entre facções do tráfico e milícias 
no Rio de Janeiro, fomentou o argumento por parte do Estado de fechar o cerco das favelas e implantar uma política de segurança pública modular tendo como finalidade as favelas.

A partir de uma parceria entre Governo Federal, Estadual e Municipal com a Secretaria de Segurança do Rio de Janeiro, o Programa UPP (Unidades de Polícia Pacificadora) - articulado pela gestão do secretário de segurança pública do Estado do Rio de Janeiro José Mariano Beltrame, promulgada pelo prefeito Eduardo Paes e pelo governador Sérgio Cabral, planejado e coordenado pela Subsecretaria de Planejamento e Integração Operacional - entrou em vigor em 2008, no Rio de Janeiro, com o objetivo de pacificar conflitos, ordenar condutas, (re)tomar territórios perdidos para o narcotráfico, integrar morro e asfalto, incluir os moradores classificados como vulneráveis e promover inclusão, participação e desenvolvimento econômico, social e ambiental sustentável com a entrada de serviços públicos, projetos sociais e também de investimentos privados nessas regiões. Desde outubro de 2012, conta também com a parceria do Ministério Público do Rio de Janeiro como facilitador das mediações de conflitos entre moradores das regiões com UPP.

As UPPs estão sendo instaladas em territórios que há anos estão ocupados por grupos de traficantes, chamados de facções criminosas e milicianos. O Programa pretende desarticular as quadrilhas ali presentes e (re)tomar esses territórios utilizando a chamada polícia comunitária ou de proximidade - estratégia de ação policial que promove a aproximação entre população civil e a polícia, utilizando tecnologias que aprimorem o trabalho policial, como o uso de "computadores, celulares, sistemas de monitoramentos, veículos com computadores, além de armamento moderno (inclusive não letal) de coletes protetores" (Cf. Fundamentos da polícia comunitária) - que também compõem a parafernália utilizada em guerras.

A pacificação prevê a instalação de 40 Unidades de Polícia Pacificadora em favelas do Rio de Janeiro. Até o momento há 36 unidades instaladas. O processo simbólico de consolidação do programa se dá no mesmo momento em que a Unidade de Polícia Pacificadora é instalada na favela. Esse procedimento passa por três etapas. Primeiro, o perfil da comunidade que será ocupada é traçado a partir de pesquisa realizada pelo IBGE que coleta dados socioeconômicos, número de domicílios, escolas, hospitais, postos de saúde, igrejas, quantidade de delitos cometidos por moradores e realiza uma análise cartográfica da região. Esta primeira fase avalia as informações obtidas e define os materiais necessários para a instalação da UPP, constituindo a equipe 
a ser formada para essa atuação. A segunda etapa, chamada Choque de Paz, consiste na ocupação territorial. Os participantes da ocupação são os agentes do Comando da Polícia Militar e o Batalhão de Operações Especiais, mais conhecido como BOPE. Podem também participar da ocupação os militares das Forças Armadas Brasileira, como aconteceu em operações de grande visibilidade, como por exemplo, a do Complexo do Alemão e a da Rocinha que se utilizaram de homens da Brigada de Infantaria Paraquedista do Exército, Blindados do Exército e da Marinha, agentes da polícia federal, militar e civil. A duração dessa fase varia de acordo com a complexidade geográfica do local e também de possíveis resistências ao programa. A terceira, e última fase, denominada "consolidação da pacificação", ocorre com a instalação efetiva da UPP.

Após sua instalação, a região passa então a ser considerada um "território pacificado" e estratégias complementares para garantir a vontade de segurança da população são desenvolvidas e aplicadas a fim de aperfeiçoar o monitoramento da favela pacificada, ressignificada como comunidade. Esse monitoramento é realizado por um conjunto de equipamentos e tecnologias como veremos a seguir que ultrapassam os sentidos da vigilância contido nas sociedades disciplinares.
Além do motopatrulhamento que vem sendo realizado em favelas de largas dimensões, a Rocinha foi a favela escolhida pela CPP (Coordenadoria de Polícia Pacificadora) ${ }^{2}$ para receber um serviço de monitoramento "especial", com o apoio de 80 câmeras em high definition de vigilância para aprimorar o trabalho dos policiais da UPP. As câmeras foram instaladas em todos os acessos à Rocinha e em pontos considerados estratégicos. Futuramente, o projeto de monitoramento contará com um software que será utilizado para o reconhecimento facial, em tempo real, de pessoas que tenham mandato de prisão. A CPP acredita na eficiência dessas câmeras, e investiu em aperfeiçoar a estratégia, junto a Polícia Militar, utilizando balões (compostos de gás hélio) de monitoramentos para captar imagens durante ações estratégicas nas designadas áreas de conflitos ou com as UPPs, podendo ser útil também para monitorar o movimento do público em grandes eventos. Quando usados, os balões ficarão a uma altura de cem metros do chão, presos ao solo por um cabo que transmitirá as imagens ao centro de controle mais próximo da região. As câmeras acopladas aos balões são uma tecnologia importada dos EUA - utilizadas pelas tropas americanas no Afeganistão -, que funcionam durante o dia ou noite e são capazes de identificar o rosto de um indivíduo a um raio de três quilômetros. 
Outra tecnologia em desenvolvimento em algumas favelas é o serviço Street View da Google Brasil que permite ao usuário conectar-se ao canal Google Maps para pesquisar um endereço. Segundo informações do portal Viva Rocinha ${ }^{3}$, a ideia de levar esse serviço para a favela se deu a fim de possibilitar, além da busca de endereços, um passeio virtual pelas chamadas comunidades. Esse serviço está sendo realizado por meio do Projeto Wikimapa, mantido por wiki-repórteres - jovens selecionados na localidade em que vivem. Os jovens recebem um treinamento rápido para utilizar o aplicativo e, em seguida, começam a mapear o território em que residem através de celular ou internet. O projeto conta com o apoio do Instituo Oi Futuro, entregou a cada jovem participante do projeto um celular com GPS para que a transmissão de informações ocorra com precisão. Além dos wiki-repórteres, qualquer pessoa pode tomar a iniciativa e inscrever-se para participar do projeto somente realizando download do aplicativo em um celular que tenha conexão com a internet.

As avançadas tecnologias de monitoramentos aqui descritas funcionam dentro da governamentalidade anteriormente apresentada. Servindo à atual política de segurança, os monitoramentos se dão por fluxos ininterruptos de controle do indivíduo, do coletivo, da circulação de toda e de cada um que compõe a população. As tecnologias de monitoramento, quando justapostas a políticas sociais e a participação dos indivíduos na política de segurança cidadã, produzem um método seguro de segurança e policiamento que se auto-regulamenta.

\footnotetext{
A segurança proporcionada pelas instituições

a ela destinada cedeu lugar ao sistema de segurança por monitoramentos, com privatizações de proteção, polícias de variedades repressivas e sociais, incógnitas ou visíveis (com preponderância destas), instituindo um sistema de visibilidades jamais alcançado pelo panóptico: o sistema funciona porque cada um também se transforma em polícia do outro (Passetti, 2011).
}

A UPP dissemina a conduta do bom policiamento em conjunto com a sociedade civil, e nesse sentido, cada indivíduo é mais uma vez atravessado pela cultura do castigo e transforma-se em polícia, revestindo a delação pela prática da denúncia social. Isso faz o sistema funcionar porque cada um também se transforma em um polícia, tal como mostrou Passetti. São outras polícias, "polícias da paz" e polícias de si que policiam um ao outro e a todos, configurando o que Passetti (2007) definiu como controle de si e dos outros. 


\section{UPP Social e seus desdobramentos}

O Programa UPP Social articula políticas e serviços municipais por meio dos vários órgãos da Prefeitura do Rio de Janeiro e funcionam apenas nas favelas que já possuem UPP. O Programa é coordenado pelo o Instituto Pereira Passos (IPP) ${ }^{4}$ e promove ações integradas com o Governo Estadual e Federal, a sociedade civil e a iniciativa privada. Cabe ainda ao IPP articular, acompanhar e integrar as ações e serviços públicos realizados no âmbito do Programa das UPPs.

Em maio de 2011, o programa firmou acordo com o ONU-Habitat (Programa das Nações Unidas para os Assentamentos Humanos) de cooperação para a execução dos projetos propostos pelo Programa, além de colaborar com o IPP na produção de dados, análises e monitoramento de cada território da UPP Social.

O objetivo geral do Programa é garantir liberdade e segurança à população; promover o desenvolvimento social e econômico; colaborar com o processo de pacificação iniciado com a instalação das UPPs; incentivar a população à prática da cidadania; integrar a cidade e eliminar fronteiras simbólicas (Cf. Programa UPP Social). Para tanto, a UPP Social está organizada em três áreas: gestão territorial (identifica demandas e cria novos canais de participação e diálogo entre população e o poder público); gestão de informações (analisa continuamente as informações quantitativas e qualitativas); gestão institucional (coordena uma rede formada por técnicos das secretarias e empresas públicas municipais para estabelecer com os representantes compromissos de acordo com a demanda de cada território em que atua).

A UPP Social afirma compartilhar responsabilidades e compromissos. Observa-se que o Programa está inserido no âmbito tanto das políticas públicas como no de assistencialismo sustentado pela iniciativa privada, pois a presença desta dentro desses projetos sociais/assistenciais se dá em um momento no qual a responsabilidade social é considerada essencial dentro de cada empresa, pois não colaborar com um programa social pode significar, muitas vezes, perda de novos negócios.

Para proporcionar à população de todas as favelas segurança, qualidade de vida e bem-estar social, o Estado investe pretendendo apaziguar a população e fortalecer a produção de cidadãos regulados, produtivos e participativos. Nesse contexto, a iniciativa privada não perde a oportunidade de negociar novos investimentos que resultam em prestígio social e, o mais importante, em lucros.

Grande parte da população, respondendo a sondagens, afirma categoricamente 
que agora se sente mais segura com a chegada da UPP. Não somente a população que vive ali e está satisfeita, mas jovens e velhos investidores dos mais variados ramos também se alegram, pois a tal segurança garantida os convocam para ali montarem seus empreendimentos e criarem laços lucrativos com novos endividados. Os investidores e também os moradores vêem na UPP uma oportunidade para aquecer a chamada economia local das favelas, atravessados pelo discurso de que a presença policial ostensiva fomenta a introdução de novos negócios na região. O diretor de uma grande rede varejista de comércio já atuante em favelas cariocas afirma: "As comunidades têm um perfil de público-alvo que corresponde ao nosso. O sucesso das lojas nesses locais é nossa assinatura embaixo da proposta de pacificação do governo" ". Afirma-se, também, que a chegada de empresas no interior das favelas representa uma questão de cidadania e inclusão. Desse modo, moradores locais se contentam em saber que a chegada da pacificação abre espaço para empreendimentos que também geram empregos, para conseguirem pagar suas dividas atuais, futuras e eternas com moedas sociais ${ }^{6}$, cartões de crédito e cheques especiais.

Os investidores não se aproximam das favelas somente com suas empresas, mas também estão ali para oferecer infindáveis cursos gratuitos ou de baixo custo volRev. Polis e Psique, 2013; 3(3):72-86 tados às mais variadas capacitações - desde que úteis para o negócio inicial, posto que os indivíduos capacitados podem servir de mão de obra para os próprios negócios que ali iniciaram, ou seja, arredondar o ciclo vicioso da filantropia lucrativa. Além de cursos de capacitação profissional, especialmente em regiões com UPP, a atuação de ONGs, institutos, associações, etc. em parceira com a UPP Social é igualmente intensificada pela "pacificação".

Segundo o Programa das UPPs e o Programa UPP Social, é preciso criar a nova geração de cidadãos a partir de uma nova perspectiva: da polícia como "cidadão de bem", que cumpre seus deveres e respeita o Direito, assim como cada uma das crianças e jovens devem ser para que tenham um futuro feliz e vivam em paz. Ocorre assim novas adaptações e capturas para que as condutas sejam governamentalizadas.

Ao mesmo tempo em que todas essas coisas se incrustam nas favelas, outro negócio lucrativo, o turismo, ganha nova dimensão e intensidade com a "pacificação". O turismo já era procurado por estrangeiros desde meados da década de 1980, mas era rara a incidência de "visitação", comparada com o que vem ocorrendo desde 2008. Agora, visitar uma favela é parte inclusiva de qualquer passeio que contemple os pontos turísticos da cidade do Rio de Janeiro, mas sempre com a recomendação de que se faça 
a visita à favela acompanhado por guias turísticos. A procura é grande, e não mais só entre os estrangeiros, mas também entre os brasileiros - segundo uma pesquisa aplicada pela $\mathrm{FGV}$, mais de $50 \%$ dos turistas estrangeiros e $58 \%$ dos brasileiros chegam à cidade com a intenção de conhecer uma favela de perto. Segundo um recente levantamento ${ }^{8}$ referente ao número de turistas que visitaram o bondinho do Pão de Açúcar e o teleférico do Complexo do Alemão em novembro de 2012, o número de visitas ao teleférico registrou mais que o dobro em relação ao bondinho do Pão de Açúcar.

Em torno dessa espetacularização da cidade, outra questão também está em jogo: a valorização imobiliária, especialmente das favelas da Zona Sul da cidade, como Vidigal e Rocinha, por exemplo. Resultado do proclamado "sucesso da pacificação" que levou investidores para essas regiões e interessados no mundo todo em viver ali - num lugar agora avaliado como uma comunidade segura e com vista linda para o mar-, o custo elevado dos alugueis promove o deslocamento de muitos moradores para outras favelas, localizadas na Zona Norte ou na Baixada Fluminense. As favelas atualmente integram um cenário quase perfeito para realização dos interesses do mercado e do Estado nestes territórios e em suas populações. Essa visibilidade também transforma a estética da favela, que passa a ganhar nome nas ruas, casas Rev. Polis e Psique, 2013; 3(3):72-86 coloridas, novas construções e reformas com o investimento dos governos em áreas de atuação específica, tal como é o Plano Municipal de Integração de Assentamentos Precários Informais lançado em julho de 2010 durante a primeira gestão no prefeito Eduardo Paes, mais conhecido como Morar Carioca. Tanto o Programa das UPPs, como todo investimento (visto como oportunidades por grande parte da população das favelas), são considerados como resultantes de melhorias nessas regiões e de acesso à cidadania. Junto com as "melhorias" chegam, também, conta de luz, de água e IPTU.

Uma das novidades no ano de 2012 que fez muito sucesso entre pobres e ricos, militares e civis, brasileiros e estrangeiros, foi a FLUPP (Festa Literária Internacional das UPP). Evento ocorrido entre 07 e 11 de novembro de 2012 no Morro dos Prazeres, em Santa Teresa, a FLUPP é um projeto inspirado na FLIP (Festa Literária Internacional de Paraty) que pretende ser um "polo da literatura" produzida no Brasil, compartilhada com o exterior. $\mathrm{O}$ evento foi idealizado a partir de uma parceria do Ministério da Cultura, Secretaria de Estado de Cultura e UPP Social, contando também com "atores sociais" públicos e privados ${ }^{9}$ para reunir autores nacionais e internacionais. $\mathrm{O}$ encontro também premiou o trabalho de formação de leitores e autores, envolvendo moradores das favelas cariocas e policiais das UPPs, 
realizado pela FLUPP Pensa cujo resultado foi sua publicação em livro, lançado durante a FLUPP. Devido ao sucesso do festival, em 2013 ocorreu sua segunda versão.

Nesse contexto, vemos que o Rio de Janeiro está por todos os lugares: na mídia on-line, impressa e televisiva; na ponta da língua dos brasileiros e dos estrangeiros; nos estudos acadêmicos nacionais e internacionais; na novela "Salve Jorge" da Rede Globo que mostrou um Complexo do Alemão habitado por gente feliz; nos melhores guias de viagem do mundo; nas mais importantes reuniões de mega-eventos e também nas discussões sobre segurança humana e cidadã. No entanto, é preciso reiterar que seu funcionamento depende da racionalidade neoliberal produzindo uma verdade para o fortalecimento do capitalismo sustentável.

Integrando à política de segurança práticas envolvendo outros setores da sociedade, ligados ou não ao Estado, a chamada segurança cidadã aliou-se a políticas sociais para garantir e legitimar seu exercício de controle. Em nome dessa segurança cidadã, legitima-se o polícia de tudo e de todos, as classificações do perigoso, as tecnologias de monitoramentos, a ampliação do fichamento, das vozes delatoras, da algema, da porrada, da tortura, dos desaparecimentos, das chacinas e das balas no peito, na cabeça ou pé, ou onde quer que seja, vindas dos fardados que se alastram. Mais sangue e mais pu- nição destinada, seletivamente, à população mapeada e classificada por vulnerável; esse código policial, social e político que faz das favelas cariocas um alvo das mais variadas políticas de segurança que chegam ali revestidas por nomes que recomendam cuidados, respeito e proximidade, tal como o atual política de pacificação composto pelo duplo UPP e UPP Social.

Mesclando militarização e monitoramento com ações sociais e polícia de proximidade, UPP e UPP Social pretendem, em conjunto, instaurar um estado de paz em oposição a um estado de guerra anterioremente caracterizado. Com seus lemas de segurança humana e segurança cidadã pautados nas diretrizes da cultura da paz e de outras normativas planetárias aqui sinalizadas, busca-se educar novas subjetividades de crianças e jovens para reconfigurar uma nova forma de cidadania por meio do controle de si e dos outros: a cidadania-polícia como fio condutor da governamentalidade das condutas.

\section{Notas}

1 Esses movimentos se desdobram em cartilhas e documentos oficiais que são amplamente divulgados pelo planeta. Entre os que estão diretamente relacionados ao meio ambiente, destacam-se a Declaração do Rio sobre meio ambiente e desenvolvimento 
(1992), Agenda 21 (1992), Carta da Terra (2000) e O futuro queremos - Declaração final da Conferência das Nações Unidas sobre desenvolvimento sustentável (2012).

${ }^{2}$ Criada através do Decreto 42787 de 06 de janeiro de 2011 com a finalidade de dirigir estrategicamente as ações e operacionalizar o plano de implantação das Unidades de Polícia Pacificadora.

${ }^{3}$ O portal Viva Rocinha $<\underline{\text { http://vivarocinha. }}$ org/portal> é "um meio de comunicação comunitária via web" criado pelos irmãos Michel Silva (19 anos) e Michele Silva (22 anos) durante a ocupação das Forças Armadas na Rocinha.

4 O Instituto Pereira Passos é uma autarquia que se dedica a produzir dados e conhecimento sobre a cidade do Rio de Janeiro, com a finalidade de apoiar a gestão pública. O IPP também planeja e coordena projetos de desenvolvimento urbano, social e econômico estratégicos para a cidade.

5 Disponível em < http://www.rj.gov.br/ web/imprensa/exibeconteudo?article$\underline{\mathrm{id}=1204835}>$ Acessado em 20/06/2013.

${ }^{6}$ Em 15 de setembro de 2011 foi lançado na Cidade de Deus o primeiro Banco Comunitário, na cidade do Rio de Janeiro, com apoio da Secretaria Especial de Desenvolvimento Econômico Solidário. O Banco Comunitário tem sido experimentado também em outras favelas. Utiliza a moeda social como dinheiro e concede crédito produtivo para beneficiários do Programa Bolsa Família, entre outras "vantagens" para a população.

${ }^{7}$ Ver cartilha feita pelo cartunista Ziraldo para conscientização das crianças sobre a "importância" do policial, no anexo deste material e disponível em $<$ http://www.upprj. com/upload/multimidia/Cartilha_Ziraldo UPP.pdf $>$ Acessado em 20/06/2013.

${ }^{8}$ Disponível em $<$ http://www.brasildefato. com.br/node/11477> Acessado em 05/06/2013.

9 Apresentado pelo BNDES, Petrobrás e Vale com patrocínio do Itaú-Unibanco, além de outras parceiras.

\section{Referências}

Cultura de paz (UNESCO), 2000. Disponível em <http://www.pucsp. br/ecopolitica/downloads/cultura da_paz.pdf> Acesso em maio de 2013.

Cultura de paz: da reflexão à ação, 2010. Disponível em $<$ http://www.pucsp. br/ecopolitica/documentos/direitos/ direitos.html>. Acesso em maio de 2013.

Democracia e Participação no contexto da crise da representação, 2008. Disponível em <http://portal.mj.gov.br/ data/Pages/MJ1BFF9F1BITEMI- 
D540715BB1C9B47D395499FA38E3E99FAPTBRNN.htm>. Acesso em outubro de 2012.

DHNET Direitos Humanos, 2000. Disponível em

$<$ http://www.pucsp.br/ecopolitica/ documentos/cultura da_paz/docs/ manifesto 2000 UNESCO cultura da paz.pdf $>$ Acesso em dezembro de 2012 .

Foucault, Michel (1988). História da sexualidade I: A vontade de saber. Tradução de Maria Thereza da Costa Albuquerque e J. A. Guilhon Alburquerque. Rio de Janeiro: Edições Graal. (1994). "Poderes e estratégias". In: Ditos e escritos - repensar a política, vol. IV. Manoel de Barros da Motta (org.). Tradução Vera Lúcia Avellar Ribeiro. Rio de Janeiro: Forense Universitária, pp. 236-246.

Fundamentos da Polícia Comunitária, Secretaria do Estado de Segurança Pública - Polícia Militar do Rio de Janeiro. Disponível em $<\underline{\text { http://solatelie.com/cfap/pdf/ }}$ PoliciaComunitaria.pdf $>$ Acesso em abril de 2013.

Manifesto 2000 UNESCO (Cultura da Paz), 2000. Disponível em

$<\underline{\text { http://www.pucsp.br/ecopolitica/ }}$ documentos/cultura_da_paz/ docs/manifesto 2000 UNESCO cultura da paz.pdf>. Acesso em abril de 2013.

Passetti, Edson. "Poder e anarquia". In: revista verve, São Paulo: Nu-sol, v. 12, 2007, pp. 11-43. "Fluxos libertários e segurança". In: Revista verve, São Paulo: Nu-sol, v. 20, 2011, pp. 49-78.

\section{Sites}

Brasil de fato http://www.brasildefato.com.br FLUPP http://www.flupp.net.br

Governo do Rio de Janeiro http://www.rio. rj.gov.br

Ministério da Justiça http://portal.mj.gov.br

Oi Futuro http://www.oifuturo.org.br

O Globo http://g1.globo.com

O Povo http://www.opovo.com.br

Projeto Wikimapa http://blog.wikimapa.org. $\underline{b r}$

Rio como vamos http://www.riocomovamos. org

UNESCO http://www.unesco.org

UPP RJ http://www.upprj.com

UPP Social http://www.uppsocial.org

Viva Rocinha http://vivarocinha.org/portal

Recebido em: 23/09/2013 - Aceito em: 11/12/2013 